\title{
ASPECTOS MATERIAIS E PROCESSUAIS DA AMMINISTRAZIONE DI SOSTEGNO ITALIANA: Comparações com a Tomada de Decisão Apoiada Brasileira
}

\author{
http://dx.doi.org/10.21527/2176-6622.2021.55.145-162
}

Recebido em: 20/3/2020

Modificações solicitadas em: 12/8/2020

Aceito em: 18/8/2020

\begin{abstract}
Gilberto Fachetti Silvestre
Autor correspondente. Universidade Federal do Espírito Santo (Ufes). Av. Fernando Ferrari, 514 - Goiabeiras. CEP 29075-910. Vitória/ES, Brasil. http://lattes.cnpq.br/7148335865348409. https://orcid.org/0000-0003-3604-7348. gilberto.silvestre@ufes.br

Guilherme Santos Neves Abelha Rodrigues Universidade Federal do Espírito Santo (Ufes). Vitória/ES, Brasil.
\end{abstract}

Igor Gava Mareto Calil

Universidade Federal do Espírito Santo (Ufes). Vitória/ES, Brasil.

\section{RESUMO}

Trata-se de pesquisa que realizou uma revisão bibliográfica sobre o instituto italiano de amparo à pessoa com deficiência/enfermidade da amministrazione di sostegno, comparando-o com as diretrizes gerais do instituto brasileiro da tomada de decisão apoiada, que tem a mesma função, a partir de seus aspectos jurídicos materiais e processuais. No Brasil, a Lei de Inclusão da Pessoa com Deficiência (Lei no 13.146/2015) incluiu o artigo 1.783-A no Código Civil, criando a tomada de decisão apoiada. A literatura jurídica brasileira aponta, desde então, que esse apoiamento se assemelha à amministrazione di sostegno do Codice Civile de Itália. Analisando material documental (julgados e bibliografia), a pesquisa respondeu ao questionamento se realmente há similaridade entre ambos os institutos, com dois objetivos: se há, quais seriam as contribuições da amministrazione di sostegno para a melhor compreensão e operabilidade da tomada de decisão apoiada; e se não há, propor que no Brasil não mais se faça a afirmação da correspondência, o que pode causar prejuízos na operabilidade desse instrumento de apoio no país.

Palavras-chave: Pessoa com deficiência. Apoio. Amministrazione di sostegno. Tomada de decisão apoiada.

MATERIAL AND PROCEDURAL ASPECTS OF THE AMMINISTRAZIONE DI SOSTEGNO IN ITALY: COMPARISONS WITH THE TOMADA DE DECISÃO APOIADA IN BRAZIL

\section{ABSTRACT}

This is a research that carried out a bibliographic review on the Italian institute of support for people with disabilities from the amministrazione di sostegno with the Brazilian institute with the same function of tomada de decisão apoiada, from its material and procedural legal aspects. In Brazil, the Inclusion Law for Persons with Disabilities (Law No. 13,146/2015) included article 1,783-A in the Civil Code, creating tomada de decisão apoiada. The Brazilian legal literature points out, since then, that this support is similar to the amministrazione di sostegno of the Codice Civile of Italy. Analyzing documentary material (judgments and bibliography), the research answer the question whether there is really similarity between both institutes, with two objectives: if any, what would be the contributions of amministrazione di sostegno to better understanding and operability of tomada de decisão apoiada; and if not, propose that in Brazil there is no more affirmation of correspondence, which can cause losses in the operability of this support instrument in country.

Keywords: Disabled person. Support. Amministrazione di sostegno. Tomada de decisão apoiada.

\section{SUMÁRIO}

1 Introdução. 20 apoio às pessoas com deficiência no Direito italiano. 3 Procedimento e causa de pedir da amministrazione di sostegno. 4 Como é a tomada de decisão apoiada brasileira? 5 Comparando a ratio juris dos institutos. 6 Conclusão. 7 Referências. 


\section{INTRODUÇÃO}

No Brasil, a Lei de Inclusão da Pessoa com Deficiência (Lei no. 13.146/2015) incluiu o artigo 1.783-A no Código Civil, criando a tomada de decisão apoiada. Desde então, apontou-se e aponta-se que esse apoiamento se assemelha à amministrazione di sostegno do Codice Civile de Itália, assim como se assimilaria à Sachwalterschaft da Áustria, à Betreuung da Alemanha, ao administrador da Bélgica, à sauvegarde de justice da França, ao apoyo da Argentina e à administración de apoyo da Espanha.

Foi realizada uma revisão bibliográfica sobre o instituto italiano de amparo à pessoa com deficiência da amministrazione di sostegno com o instituto brasileiro com a mesma função da tomada de decisão apoiada, a partir de seus aspectos jurídicos materiais e processuais.

Apesar da afirmação de semelhança, esta pesquisa investigou - no âmbito de projeto de iniciação científica (PRPPG/Pivic/CNPq) - se existe no Brasil material bibliográfico que abordasse em profundidade os aspectos jurídicos materiais e processuais da amministrazione di sostegno, cujo resultado não foi satisfatório. $\mathrm{Na}$ amostragem colhida não se verificou existirem trabalhos específicos sobre o tema, mas alusões em teses e dissertações sobre esse apoiamento. Por isso, a pesquisa pretendeu inovar quanto a essa possível falha, fazendo uma análise em língua portuguesa sobre a amministrazione di sostegno, com o objetivo de facilitar sua compreensão.

Foram tratadas as diretrizes gerais da tomada de decisão apoiada para focar e aprofundar de modo especial no instituto italiano. A intenção é apresentar a amministrazione di sostegno e demonstrar que ambos os institutos guardam substanciais diferenças na concepção e no procedimento. $O$ objeto de aprofundamento foi o instituto italiano. Passados cinco anos da existência da tomada de decisão apoiada no Direito brasileiro e a quantidade de trabalhos já publicados, não justificaria aprofundar este item do trabalho. O conhecimento da tomada de decisão apoiada, portanto, é pressuposto de leitura deste texto, pois o instituto brasileiro foi analisado apenas em aspectos gerais, para compreender sua diferença de concepção em relação ao instituto italiano. Fica esclarecido, assim, que nosso objetivo não é desenvolver a tomada de decisão apoiada; conhecê-la em detalhes é um pressuposto de leitura e compreensão deste trabalho.

Analisando o material documental da amostra (julgados e bibliografia), a pesquisa respondeu ao questionamento se realmente há similaridade quanto à ratio juris e outros elementos entre ambos os institutos e qual a repercussão de tal e possível similitude, sempre com dois objetivos: se há semelhança, quais seriam as contribuições da amministrazione di sostegno para a melhor compreensão e operabilidade da tomada de decisão apoiada; e se não há, propor que no Brasil não mais se faça a afirmação da correspondência, o que pode induzir a um erro que causaria prejuízos na operabilidade desse instrumento de apoio no Brasil.

Espera-se, com esta pesquisa, oferecer à comunidade jurídica um material que possa contribuir para a compreensão da tomada de decisão apoiada, que, mesmo completando seis anos de vigência em 2021, apresenta dúvidas quanto à sua operabilidade. Do mesmo modo, a amministrazione di sostegno - que conta com uma experiência jurídica mais antiga, datada de 2004 - pode oferecer importantes elementos práticos para a tutela da pessoa com deficiência, sempre no seu melhor interesse.

\section{O APOIO ÀS PESSOAS COM DEFICIÊNCIA NO DIREITO ITALIANO}

Em meio a um movimento de valorização e de inclusão das pessoas com deficiência e dos enfermos psicossomáticos (mentais e físicos), a Lei no 6, de 9 de janeiro de 2004, criou um paradigma no que se refere ao tratamento dispensado a eles na Itália. Assim, pautando-se na tutela de seus direitos com a menor restrição possível da capacidade de agir, houve uma ruptura com o modelo tradicional de proteção daqueles indivíduos, adquirindo relevo ético-social (BONILINI; TOMMASEO, 2008, p. 8). Promoveu, portanto, o apoio para o desenvolvimento da autonomia e exercício da capacidade, transcendendo a esfera da proteção patrimonial. Nesse sentido, assim dispõe o artigo 10 da Legge 9 gennaio 2004, n. 6: “Art. 1 - La presente legge ha la finalità di tutelare, con la minore limitazione possibile della capacità di agire, le persone prive in tutto o in parte di autonomia nell'espletamento delle funzioni della vita quotidiana, mediante interventi di sostegno temporaneo o permanente". 
Esse movimento de mudança da percepção e do tratamento dos indivíduos com deficiência física e mental/intelectual, sacramentado pela Lei no 6/2004, iniciou-se mormente com as transformações da forma com a qual se enxerga tais sujeitos. Verifica-se uma ruptura com a classificação de enfermidade/deficiência segundo critérios exclusivamente médicos e técnicos, que acabavam por instituir estigmas e preconceitos, permitindo a difusão de tratamentos e cuidados inclusivos essenciais para essas pessoas.

A legislação vigente na Itália até a década de 50 do século 20, incentivava um tratamento "di tipo custodialistico e di polizia, e non come tratamento positivo sulla salute della persona" (BUGETTI, 2007, p. 7). Essa concepção tem origem na Lei no 36 de 14 de fevereiro de 1904, que traz as disposições sobre manicômios e alienados e a custódia dos alienados, instituindo logo, em seu artigo 1ㅇ, que a internação dos indivíduos "alienados mentais" [sic] deveria ocorrer quando pudessem oferecer algum tipo de periculosidade ao meio social. Essa norma, que remonta há mais de cem anos, inspirava-se em outra ainda mais antiga, qual seja, a Loi Esquirol francesa de 1838, fomentadora do estigma de que as pessoas com deficiências mentais eram indesejáveis e perigosas (GARGANI, 2015-2016, p. 2). É evidente que as medidas vigentes na época não buscavam a tutela da pessoa e de sua autonomia, mas sua exclusão do convívio social com o objetivo de preservar direitos de terceiros.

Com a vigência da Costituzione Della Repubblica Italiana em 1947, e diante das novas concepções médicas acerca de enfermidades mentais e físicas, iniciou-se um movimento para dar maior atenção e preocupação à preservação da autonomia e autodeterminação da pessoa. Assim, em 1986, juristas e médicos psiquiatras italianos reuniram-se em Trieste com o intuito de propor uma reforma do Codice Civile acerca do status dos sujeitos não autossuficientes, principalmente aqueles com deficiências mentais, que ficou conhecida como Bozza Cendon (GARGANI, 2015-2016, p. 8).

Nota-se, portanto, o estímulo à criação de normas jurídicas com essa mesma intenção de dar especial amparo às pessoas com deficiência e garantir sua cidadania, conforme destaca Roberto Masoni (2009, p. 39): "La disciplina, infatti, ha un alto contenuto sociale, ed è una risposta di cilviltà per la salvaguardia della qualità e della dignità della vita, como tutelati dalla nostra Carta fondamentale".

É nesse contexto que aparece a Lei no 6 de 9 de janeiro de 2004, que inovou ao criar o instituto da "amministrazione di sostegno", um instrumento de apoio mais flexível e menos invasivo, moldado às particularidades do caso concreto, que se propôs a mitigar a burocracia características dos institutos de interdizione e inabilitazione, os quais voltam-se mormente à esfera patrimonial, em detrimento da tutela plena dos aspectos existenciais. Nicola Orlando (2013, p. 49-50), a propósito, destaca a morosidade e a burocracia características desses tradicionais institutos italianos.

De igual maneira, a Lei no 6/2004 conferiu maior possiblidade de adequação da medida de apoio às específicas necessidades e anseios do beneficiário, buscando ao máximo a preservação de sua autonomia. Assim, o novel instituto transcendeu o binômio da "deficiência mental-incapacidade", que tinha um exclusivo olhar às causas de incapacidade, e passa a atentar-se, sobretudo, às impossibilidades práticas decorrentes da deficiência ou enfermidade na vida do sujeito. Trata-se do chamado conceito social de deficiência.

\section{PROCEDIMENTO E CAUSA DE PEDIR DA AMMINISTRAZIONE DI SOSTEGNO}

Para melhor compreender o instituto, é possível traçar a seguinte sistematização geral do regime jurídico da amministrazione di sostegno, prevista nos artigos 404 a 413, entre outros, do Codice Civile italiano.

Quanto à legitimidade ativa, o artigo 406 do Codice Civile estabelece que estão legitimados para requerer a amministrazione di sostegno: 1) o próprio beneficiário, mesmo que menor, interditado ou inabilitado; 2) o cônjuge; 3) o convivente; 4) os parentes de até quarto grau; 5) aqueles com quem se mantém relação de até segundo grau; 6) o tutor; 7) o curador; e 8) o Ministério Público, que pode intervir em qualquer caso, mesmo quando não tiver sido aquele que requereu a constituição do apoio.

Os agentes do Serviço Social e de Assistência à Saúde, diretamente empregados na cura e assistência da pessoa, que tiverem conhecimento de fatos que justifiquem a constituição da amministrazione, devem dar início ao procedimento ou comunicar o Ministério Público para que este o requeira. Isto é, possuem legitimidade ativa para requerer a constituição da amministrazione di sostegno, e devem tomar as medidas cabíveis caso se defrontem com indivíduos que julguem necessitar do apoio, conforme disposto no artigo 406 c/c artigo 407. 
O artigo 404 do Codice Civile estabelece quem pode ser beneficiário do instituto, ou seja, quem pode ser assistido por um administrador de apoio, que são os enfermos e os deficientes físicos e psíquicos que estiverem impossibilitados, parcial ou temporariamente, de prover aos seus próprios interesses. Sobre o significado de enfermidade, Maria Novella Bugetti (2007, p. 33) esclarece:

Quanto alla definizione dell'infermità, sembra che possano trovare applicazione le elaborazioni messe a punto nell'ambito di interdizione e inabilitazione, che definiscono la malattia mentale come alterazione patologica o processo morboso che "disturbando e dissolvendo l'attività psichica, diminuisce la libertà e la responsabilità del soggetto", indipendente da una sua connessione con il sistema nervoso.

Note que, diferentemente do instituto brasileiro da tomada de decisão apoiada (1.783-A do Código Civil c/c Lei no. 13.146/2015), o apoio italiano não é limitado apenas às pessoas com deficiência, abrangendo também os enfermos. Além disso, há de se atentar a algumas hipóteses de possíveis beneficiários da amministrazione di sostegno, a fim de melhor examinar a possibilidade de sua aplicação.

Apesar de grande parcela dos beneficiários ser composta por idosos, a senilidade, de per si, não lhes confere o direito de requerer e, eventualmente, beneficiar-se do apoio, conforme destacam Stefania Monosi e Nicola Taccone (2016, p. 2):

Questa soluzione è stata accolta anche da una parte della giurisprudenza di merito che, in un recente provvedimento - Tribunale di Vercelli, 16 ottobre 2015, in CNN notizie del 4 dicembre 2015 -, ha stabilito l'inadeguatezza della nomina di un amministratore per l'ipotesi di un soggetto molto anziano ma privo di alcun deficit delle capacita cognitive. Si è ritenuto che, in presenza di un soggetto pienamente capace, la risoluzione di alcune problematiche della vita quotidiana può essere realizzata attraverso l'istituto del mandato, non rinvenendosi la necessità di privare il soggetto seppur in maniera minima della capacità di agire [...].

É impreterível que se enquadrem em algum dos requisitos do artigo 404, isto é, ser enfermo, deficiente físico ou psíquico, e estar impossibilitado de prover seus próprios interesses, conforme analisou Damiano Gargani (2015-2016, p. 40): "equivale a dire, che ne esulano le ipotesi di mera difficoltà: in tal caso si dovrebbe ricorrere ad altri strumenti giuridici e non all'amministrazione di sostegno che comporta, almeno in parte, una privazione della capacità d'agire".

Há, todavia, na literatura jurídica italiana quem entende que as dificuldades geradas pela senilidade poderiam ensejar a aplicação do instituto de apoio, independentemente de deficiência, a exemplo de Maria Novella Bugetti (2007, p. 35):

Ciò non di meno, spesso accade che la vecchiaia - eventualmente anche in mancanza di alcuna patologia mentale - determini una limitazione apprezzabile delle funzioni della vita quotidiana, con conseguente impossibilità di provvedere adeguatamente ai propri interessi. Come ha sottolineato la giurisprudenza, l'amministrazione di sostegno ben risponde alle esigenze di protezione del soggetto in età avanzata, perché consente di assolvere la funzione di protezione e assistenza, senza in alcun modo pregiudicare la personalità dell'anziano,

Tal e qual a senilidade, a prodigalidade, de per si, não legitima a constituição do instrumento de apoio em questão. Afinal, não é considerada uma doença, mas tão somente um desvio de personalidade que pode se manifestar em algumas patologias ou deficiências mentais, quando caberia a aplicação do instituto (GARGANI, 2015-2016, p. 48). Não é, portanto, a prodigalidade, mas a causa de que é sintoma que figura como requisito para a aplicação da amministrazione di sostegno.

Esta pesquisa revelou que, a partir de uma interpretação literal do artigo 404, há quem compreende na literatura jurídica italiana que a dependência alcóolica e toxicológica (ébrios habituais e viciados em narcóticos) não figura como enfermidade ou deficiência mental. Não caberia, então, a aplicação da amministrazione di sostegno, que limitaria desnecessariamente a capacidade de agir do indivíduo. Esse é o entendimento, por exemplo, de Flavio Takanen (2019, p. 59): "Sul punto si ricorda che la maggioranza della dottrina e giurisprudenza ritiene che la misura di sostegno, nel caso di abuso di sostanze alcholiche o stupefacenti, non possa essere adottata nel caso vi sia um abuso abituale non grave, che non abbia provocato alterazione delle facoltà mentali". 
Em contrapartida, há autores, pautando-se no princípio da dignidade humana, que entendem que a constituição do apoio seria capaz de satisfazer e auxiliar na recuperação dos sujeitos dependentes do álcool e de entorpecentes, privados de parte de sua autonomia e socialmente marginalizados (GARGANI, 2015-2016, p. 53).

Ambos os posicionamentos partem da premissa de que a dependência alcóolica e toxicológica não figura como enfermidade ou deficiência mental. A Classificação Estatística Internacional de Doenças e Problemas Relacionados com a Saúde (CID), da Organização Mundial da Saúde (OMS), todavia, considera que elas são patologias, catalogadas sob o CID 10 - F10 a F19 (transtornos mentais e de comportamento em razão do uso de substâncias psicoativas) (LEMOS, 2010). Questiona-se, portanto, as interpretações mencionadas, de modo a entender que os ébrios habituais e viciados em narcóticos enquadrar-se-iam na fattispecie do artigo 404.

Outros possíveis beneficiários são as pessoas com deficiência ou enfermidade físicas que são compos sui. Nesse caso, apesar da presença de enfermidade ou deficiência física, não há impossibilidade, mas apenas uma dificuldade no desempenho de suas funções. Esses indivíduos são, como costuma-se denominar na literatura, compos sui. Sobre essa questão, há quem defende que, como não haveria impossibilidade de prover aos próprios interesses, seria incabível a aplicação do instituto de apoio, como Livia Di Bello (20142015, p. 20):

Vi è infatti chi ritiene che la persona che abbia piena lucidità mentale e sia costretta a casa o al ricovero in quanto non deambulante, una persona anziana che, ad esempio, si muove con l'utilizzo di presidi, come carrozzine, si trova non nell'impossibilità di provvedere ai propri interessi, ma nell'inattitudine di provvedere direttamente per gravi ostacoli, ha diritto ad una rappresentanza attraverso strumenti negoziali come procura e mandato, non ala nomina di un amministratore che comunque limita le capacità di un soggetto

Em sentido semelhante, Damiano Gargani (2015-2016, p. 60) assevera:

Secondo tale orientamento, nel caso di persona inferma o menomata nel fisico, ma perfettamente compos sui, non si concretizza il presupposto dell'impossibilità a provvedere ai propri interessi, quanto piuttosto va riconosciuta la sua inattitudine a provvedervi direttamente. In questi casi l'accesso al nuovo istituto comporterebbe uma inammissibile rinuncia alla propria capacità d'agire, di fronte alla quale, il giudice perderebbe quella discrezionalità che le norme sull'amministrazione di sostegno gli conferiscono

Tal argumento funda-se na ausência do requisito de impossibilidade do artigo 404 e no exposto pelo artigo 10 da Lei no 4/2004, que institui como finalidade da norma a menor limitação possível da capacidade de agir dos sujeitos. Desse modo, entende-se que se o indivíduo não se encontra impossibilitado de desempenhar suas atividades e pôr em prática seus interesses, não seria coerente a nomeação de um amministratore di sostegno, que acarretaria em uma redução desnecessária de sua capacidade de agir. Afinal, a dirimência dessa "dificuldade" para prover aos próprios interesses poderia se dar por um instrumento de representação voluntária, menos invasivo, formal e gravoso.

Tal argumento, no entanto, tem como premissa que a amministrazione di sostegno, impreterivelmente, reduz a capacidade de agir do beneficiário. Contrariando tal entendimento, outros autores vislumbram a possibilidade dos enfermos ou das pessoas com deficiência, mas compos sui, serem beneficiários do apoio sem que haja prejuízo à sua capacidade.

Nesse caso, seria o administrador um mero conselheiro que apenas auxiliaria o administrado, sem que isso significasse redução em qualquer grau de sua autonomia. Essa questão traz, todavia, questionamentos ainda mais amplos: seria a amministrazione di sostegno cabível quando outra opção menos drástica fosse adequada para a tutela do indivíduo? Aplicando as disposições alemãs do Breteuung ao ordenamento jurídico italiano, a amministrazione di sostegno apenas poderia ser deferida quando realmente necessária.

O Betreuung, cabe explicar, é um instrumento de apoio alemão similar à amministrazione di sostegno, que, entre seus requisitos de aplicação, requer a necessariedade do apoio, isto é, a constituição do instituo dar-se-á apenas nos casos em que, de fato, for necessário, principalmente quando a tutela da pessoa não puder ser prestada por outros instrumentos (§ 1896, II, Bürgerliches Gesetzbuch) (BUGETTI, 2007, p. 37-40). 
Aponta Maria Novella Bugetti (2007, p. 37-40) que, tendo a amministrazione di sostegno um caráter mais formal e publicístico, com a presença de um juiz fiscalizador, o conceito de necessariedade não seria uniforme, pois confere diversas garantias ao sujeito para além da dirimência de sua impossibilidade, sendo, portanto, ao mesmo tempo um instrumento de apoio e garantia para o beneficiário.

Sobre a figura do amministratore ("apoiador"), considerando que o artigo 411 do Codice Civile determina a aplicação por analogia de demais dispositivos legais à amministrazione di sostegno - além daqueles que versam especificamente sobre o instituto -, pode-se inferir da leitura do artigo 350 do Codex que não podem ser nomeados amministratori: 1) aqueles que não administrem seu próprio patrimônio; 2) aqueles que foram excluídos da tutela por disposição escrita do genitor, que por último exerceu o pátrio poder; 3) aqueles que tenham, ou venham a ter, ascendentes, descendentes ou cônjuge, em litígio com o administrado; 4) aqueles que foram destituídos anteriormente da função de amministratore; 5) os falidos/insolventes ou aqueles que enfrentam processo de falência; e 6) o servidor público ou privado que esteja participando da curadoria e proteção do doente (artigo 408).

De igual maneira, a partir da interpretação do artigo 351, pode-se concluir que estão dispensados do ofício de amministratore: 1 ) os príncipes da Família Real, salvo legislação especial (sob dessuetude, uma vez que a Itália é hoje uma república); 2) o Presidente del Consiglio dei Ministri della Repubblica Italiana ("Primeiro Ministro"), ou seja, o chefe do governo (Capo del governo) (anteriormente, a dispensa se referia ao presidente del Consiglio del Regno d'Italia); 3) os membros do Colégio dos Cardeais da Igreja Católica Apostólica Romana; 5) o presidente da Assembleia Legislativa; e 5) os ministros secretários de Estado.

Destaca-se que, com exceção dos membros da antiga Família Real da Casa de Savoia, os demais indivíduos supraindicados podem optar por não serem dispensados, devendo para isso, informar tal intenção ao juiz.

Há, ainda, a possibilidade de demais indivíduos serem dispensados da função de administrador. Diferentemente dos mencionados no artigo 351, que têm sua dispensa presumida, estes devem requerê-la ao juiz antes do juramento, por meio da domanda di dispensa, sob pena de decadência do direito de modificar a situação jurídica, conforme artigo 353, comma 1: “Art. 353. (Domanda di dispensa). La domanda di dispensa per le cause indicate nell'articolo precedente deve essere presentata al giudice tutelare prima della prestazione del giuramento, salvo che la causa di dispensa sia sopravvenuta. [...]". Assim, o artigo 352 determina que possuem esse direito de pleitear a dispensa: 1) os oficiais de Estado de alto escalão que não foram indicados no dispositivo supra; 2) os arcebispos, bispos ou ministros de cultos religiosos; 3) os militares em ativa; 4) os maiores de 65 anos; 5) aqueles que possuem mais de 3 filhos menores; 6) os que exercem outra função de apoio, representação ou assistência; e 7) aqueles que estejam em missão do governo italiano no exterior ou que residam fora do país em razão de serviço público.

Aquele que requerer a dispensa deve assumir e permanecer na função de administrador até que o apoio seja conferido a outra pessoa, como estabelece o artigo 353, comma 2: "Art. 353. [...]. II tutore è tenuto ad assumere e a mantenere l'ufficio fino a quando la tutela non sia stata conferita ad altra persona".

O ricorso (requerimento) da amministrazione di sostegno deve indicar, conforme o artigo 407, comma 1, do Codice Civile: 1) os aspectos/características gerais do beneficiário; 2) sua residência habitual; 3) a causa de pedir, isto é, a razão pela qual se está requerendo um amministratore di sostegno; e 4) o nome e o domicílio, se conhecidos pelo requerente, do cônjuge, dos descendentes, dos ascendentes, dos irmãos e dos conviventes do beneficiário.

Destaca-se que, segundo decisão da Corte di Cassazione Civile, não se faz necessária a presença de um advogado no procedimento, exceto se a questão a ser decidida pelo giudice tutelare envolver direitos fundamentais do beneficiário, caso em que há a necessidade de defesa técnica (Corte di Cassazione Civile, I sez., Sentenza n. 25366, 29 novembre 2006).

Outra questão é o Decreto di nomina. O giudice tutelare, antes de deferir a constituição da amministrazione di sostegno, deve analisar se o administrando preenche os requisitos do artigo 404, quais sejam, os critérios subjetivos (menomazione ou enfermità) e objetivos (impossibilità). Segundo Maria Novella Bugetti (2007, p. 36), tal padrão de proceder segue o modelo germânico: "Cogliendo pertanto lo spunto classificatorio 
adottato dalla dottrina tedesca, potrebbe affermarsi che la malattia e la menomazione fisica o psichica costituiscono i presupposti soggettivi dell'amministrazione di sostegno, mentre l'impossibilità (Unvermögen zur Besorgung einzelner Angelegenheiten) il presupposto oggettivo".

Diante disso, parte da giurisprudenza di merito entende ser o critério objetivo o determinante para que a amministrazione di sostegno seja deferida. Isto é, o instituto não tem causa na enfermidade ou na deficiência por si só, mas nos efeitos práticos decorrentes destas na vida do administrando (Corte di Cassazione Civile, I sez., Sentenza n. 25366, 29 novembre 2006). Além disso, deve o juiz ouvir os interessados, podendo dispor de todos os meios instrutórios necessários, inclusive de natureza médica, para que possa decidir, conforme restou consignado na decisão da Corte di Cassazione Civile, I sez., Sentenza n. 25366, 29 novembre 2006:

Invero in una pronuncia di taglio processuale e che sul punto scarsamente argomenta - il giudice tutelare, a differenza del giudice dell'interdizione e dell'inabilitazione, non si muove "nell'ottica di accertare l'incapacità di agire" dell'interessato, quanto piuttosto al fine di fornire sostegno a chi si trovi impossibilitato a curare autonomamente i propri interessi.

O Decreto di nomina é moldado casuisticamente pelo giudice tutelare, que deve considerar as específicas necessidades e anseios do beneficiário, cuidando para a maior manutenção possível de sua autonomia (CASSANO, 2006, p. 69), isto é, atribui-se ao instituto um caráter elástico e modular (RIBEIRO, 2016, p. 64). Assim, o decreto deve conter: 1) as características/aspectos gerais do beneficiário e do administrador; 2) o prazo de vigência do apoio, que pode ou não ser determinado; 3) o objeto do apoio e os atos que o administrador pode exercer em nome e por conta do beneficiário; 4) os atos que o beneficiário pode realizar apenas quando assistido pelo administrador; 5) os limites, que podem ser periódicos, das despesas que o administrador pode pagar com a soma monetária de que dispõe, ou pode dispor, o administrado; e 6) a periodicidade com que o administrador deve relatar ao juiz sobre a atividade desenvolvida e as condições de vida pessoal e social do beneficiário.

Uma questão que divide a jurisprudência italiana é a nomeação de um administrador de suporte para a curadoria de pessoas plenamente capazes, mas que estão na iminência de estarem impossibilitadas de prover seus próprios interesses. Por um lado, a Corte di Cassazione decidiu, em 2012, pela impossibilidade de se nomear antecipadamente um amministratore (Corte di Cassazione Civile, sez. I, no 23.707, 20 de dezembro de 2012). Argumentou-se que, a partir da interpretação do artigo 404 do Código Civil, a amministrazione di sostegno somente poderia ser constituída para aqueles indivíduos que preenchessem os requisitos subjetivos e objetivos sobre os quais versa a norma jurídica, ou seja, é necessário que o sujeito apresente tanto uma enfermidade/deficiência quanto esteja impossibilitado de prover seus próprios interesses em momento pretérito ao ricorso que inicia o procedimento.

Em 2014, todavia, o Tribunale di Modena (Tribunale di Modena 24 febbraio 2014 e Tribunale di Modena, 30 novembre 2014. II G.T. dott. Roberto Masoni), ainda que contrariando, em certa medida, a Cassazione, autorizou a nomeação do amministratore, sob o fundamento da tutela plena e efetiva do sujeito, conforme a finalidade do instituto. Entendeu, portanto, que seria possível a nomeação de um administrador para um indivíduo que se encontrava na iminência de se tornar impossibilitado de prover seus próprios interesses. Deve-se esclarecer que, nesses casos, o sujeito já deve atender aos requisitos subjetivos, estando ausente apenas o critério da impossibilidade, que virá a se materializar em um futuro próximo.

Ressalte-se que nos casos em que o beneficiário for um menor de idade não emancipado, o decreto judicial somente poderá ser proferido no último ano antes da maioridade, ou seja, aos 17 anos, estando os efeitos do pronunciamento judicial condicionados ao alcance da maioridade (18 anos), conforme artigo 406 do Código Civil.

De acordo com o artigo 408 do Codice Civile, a escolha do amministratore di sostegno deve ter em vista o resguardo e o cuidado do beneficiário, assim como a preservação de seus interesses. O amministrato tem o direito potestativo de escolher o amministratore di sostegno. Tal escolha, entretanto, deve ser realizada anteriormente à situação de impossibilidade, mediante ato público ou escritura privada autenticada, podendo ser revogada da mesma forma, conforme destaca Damiano Gargani (2015-2016, p. 122): "L'atto di designazione si presenta come un atto di previdenza, una manifestazione di volontà, che l'interessato può compiere in qualsiasi momento della propria vita, sia qualora l'esigenza dell'amministrazione di sostegno si riveli ipotetica, sia in prossimità della sua attivazione". 
Caso o beneficiário não tenha exercido antecipadamente seu direito de escolha, ou na presença de graves motivos que o impeçam de fazê-lo, cabe ao giudice tutelare designar o administrador por meio de decreto motivado. Sendo possível, deve o juiz priorizar na escolha (artigo 408, comma 1): 1) o cônjuge; 2) o convivente; 3) os ascendentes; 4) os descendentes; 5) os irmãos; 6) os parentes até quarto grau; e 7) o sujeito designado pelo genitor sobrevivente em testamento, instrumento público ou escritura privada.

$\mathrm{Na}$ ausência das indicações anteriores, ou nos casos em que o sujeito não possua um círculo familiar ou não se relacione com os indivíduos do rol do artigo 408, comma 1, o magistrado pode designar outra pessoa idônea: "Possono essere esclusi anche coloro che possiedono potenzialmente i requisiti necessari alla nomina se versino in una condizione che li renda immeritevoli dell'ufficio o che possa determinare la loro rimozione" (DI BELLO, 2014-2015, p. 24).

Note-se que, com vistas a evitar conflitos de interesse, não podem exercer o cargo de amministratore os indivíduos operadores de serviços públicos e/ou privados diretamente encarregados do cuidado e da proteção do beneficiário.

Há de se esclarecer uma questão acerca do artigo 408, que autoriza a indicação antecipada do amministratore, mediante atto pubblico ou scrittura privata autenticata. A partir dessa norma as pessoas passaram a produzir documentos em que, além da designação/indicação do administrador, estabeleciam os atos a serem cumpridos, o objeto do apoio, as eventuais hipóteses de enfermidade/deficiência, etc. Isto é, criavam um documento privado que pretendia designar um administrador para a realização de determinados atos em caso de ocorrência da condição suspensiva (eventual futura incapacidade). Assim, no ricorso apresentado ao giudice tutelare, juntava-se o instrumento privado e se requeria que fosse determinada a nomeação condicional de um administrador segundo as determinações realizadas pelo próprio beneficiário no instrumento privado, que, deve-se ressaltar, ainda não se encontrava enfermo/deficiente/impossibilitado.

Após ter dividido a jurisprudência italiana entre aqueles que aceitavam (Tribunale di Modena, decreto del 5 novembre 2008, G. T. dott. Guido Stanzani e Tribunale di Parma, decreto no 536 del 2 aprile 2004) ou não (Tribunale di Mantova, decreto del 24 de luglio 2008, G.T. dott. ssa. Jessica Bonetto e Tribunale di Roma, decreto del 10 aprile 2009, G.T. dott.ssa. Chiara Giammarco) tal requerimento, em 2012 a Corte di Cassazione proferiu decisão que enfrentou a quæstio iuris, qual seja, a dúvida se seriam os requisitos subjetivos e objetivos do artigo 406 (deficiência/enfermidade e impossibilidade) pressupostos para a abertura do procedimento de amministrazione ou somente para a eficácia do decreto. Nessa mesma oportunidade discutiu-se se o beneficiário poderia designar antecipadamente ou não, além do administrador, as diretivas e vontades a serem cumpridas no eventual apoiamento.

Assim, a corte superior (Corte di Cassazione) determinou que não é cabível a nomeação condicional (nomina ora per allora) de um administrador de apoio. Por outro lado, na segunda questão, enfrentados os argumentos de que tais disposições seriam decorrentes do direito fundamental à autodeterminação e à saúde, entendeu que, além da indicação da pessoa do amministratore (artigo 408), o eventual beneficiário também pode manifestar antecipadamente essas diretivas a serem observadas no desenvolvimento do apoio. Tais disposições pretéritas ao próprio procedimento da amministrazione di sostegno, porém, não têm o condão de constituir uma verdadeira amministrazione di sostegno, ainda que tenham eficácia na esfera privada e sejam levadas em consideração pelo giudice tutelare. Dessa forma, a escolha antecipada do administrador e a indicação dos desejos/diretivas não pode ser utilizada para a obtenção de uma nomeação antecipada - o que se costuma chamar de "nomina ora per alora" -, sendo a especificação dos atos/deveres e objeto do apoio de competência exclusiva do juiz tutelar (VIMERCATI, 2012).

O Tribunale di Modena, em 2014, todavia, decidindo de modo contrário à Corte di Cassazione, aceitou a nomeação condicional para aqueles indivíduos que estão na iminência de se tornarem impossibilitados de proverem aos próprios interesses (Tribunale di Modena, decreto del 5 novembre 2008, G. T. dott. Guido Stanzani e Tribunale di Parma, decreto no 536 del 2 aprile 2004). Observe, assim, que existe um dissenso jurisprudencial.

No que se refere ao prazo de vigência, o artigo 405 do Codice Civile determina que a amministrazione di sostegno pode ou não ter prazo determinado. Em ambos os casos, deve constar o que fora decidido no decreto de nomeação prolatado pelo giudice tutelare. Caso o prazo de vigência do instituto seja determinado, antes de seu término pode o juiz, inclusive ex officio, prorrogá-lo mediante decreto fundamentado. 
Ao contrário da tomada de decisão apoiada no Brasil (artigo 1.783-A do Código Civil), o Codex italiano estipula uma limitação temporal ao exercício da função de administrador, com vistas a evitar que ele permaneça no encargo por tempo indefinido (GURGEL, 2019, p. 116). Assim, o mesmo indivíduo não é obrigado a desempenhar a função de administrador por mais de dez anos consecutivos, de acordo com o artigo 410, comma 3. Tal regra, no entanto, não se aplica ao cônjuge, ao ascendente, ao descendente ou ao companheiro (união estável).

Destaca-se que não há limitação para a vigência do instituto, apenas para o período de desempenho da função pelo mesmo apoiador.

Nos casos em que houver necessidade, o juiz pode - inclusive ex officio - decretar um provimento de urgência visando o cuidado da pessoa apoiada e a conservação e administração de seu patrimônio, e, de igual maneira, pode nomear um administrador de apoio provisório, delimitando os atos que ele pode vir a desempenhar. Trata-se da amministrazione di sostegno provisória do artigo 405, comma 4.

A amministrazione di sostegno tem por escopo limitar ao mínimo possível a capacidade de agir do beneficiário (GURGEL, 2019, p. 152), servindo como uma medida menos severa quando comparada à interdizione e à inabilitazione.

O artigo 405, comma 5, do Codice Civile, permite que o beneficiário seja assistido em alguns atos, que seja representado em outros ou até mesmo que os exerça livremente, conforme o que for estabelecido pelo Decreto di nomina. Ou seja, nas situações em que se demande a assistência ou representação do administrador, a capacidade de agir do beneficiário é diminuída. O amministrato conserva, todavia, sua capacidade para todos os atos que pode realizar por si só: "Il beneficiario non è un incapace, ma una persona che incontra alcune limitazioni della propria capacità in relazione a determinati atti ed in considerazione della propria situazione di debolezza" (DI BELLO, 2014-2015, p. 26).

Logo, apesar das restrições que, eventualmente, venha a sofrer em sua capacidade, o administrado pode, em qualquer hipótese, praticar todos os atos necessários à satisfação das exigências de sua vida cotidiana.

O artigo 412 do Codice Civile estabelece que os atos realizados pelo amministratore que violarem a lei e excederem o objeto do apoio ou os poderes conferidos pelo juiz, podem ser anulados a partir de requerimento do próprio administrador, do Ministério Público, do beneficiário ou dos herdeiros e sucessores.

Por outro lado, os atos realizados pessoalmente pelo beneficiário que violem a lei ou as determinações do apoio, podem ser anulados a partir do requerimento do próprio administrado, do administrador e dos herdeiros e sucessores.

O direito de anular tais atos decai em cinco anos, contados a partir do momento em que cessa o estado de sujeição do indivíduo à amministrazione di sostegno.

É possível que exista, ainda, o chamado contrasto entre o apoiador e o apoiado, caracterizado pela divergência entre a vontade do administrado e a orientação do administrador.

Entre os deveres imputados ao amministratore pelo artigo 410, tem-se a obrigação de informar tempestivamente ao juiz os casos de "dissenso" com o beneficiário, devendo o magistrado intervir nos casos de "contrasto" (conflito) para dirimir a divergência e decidir sempre no melhor interesse do amministrato.

Há, na literatura jurídica, quem diferencia contrasto de dissenso: o primeiro consiste em um desacordo mais duradouro e fundamentado, enquanto o segundo é uma mera divergência: "il termine "contrasto" non si intende un qualunque disaccordo tra beneficiario ed amministratore, bensì, una prolungata e fondata divergenza sulle scelte effettuate dall'amministratore" (BUGETTI, 2007, p. 151).

Enfim, deverá o giudice tutelare intervir nos casos em que julgar adequado, adotando as providências necessárias, segundo o grau e o tipo de divergência. Além disso, havendo contrasto, escolhas ou atos potencialmente prejudiciais, ou negligência na efetivação dos interesses e/ou solicitações do apoiado, cabe ao beneficiário, ao administrador, ao Ministério Público ou aos sujeitos elencados no rol do artigo 406, comunicar ao juiz, que determinará as medidas necessárias por meio de um decreto justificado.

Nesse contexto, é de se questionar qual, afinal, é o objeto do apoio do instituto italiano. 0 artigo 405, comma 5, n. 3, dispõe que cabe ao giudice tutelare determinar, por meio do Decreto di nomina, o oggetto dell'incarico - o que pode ser entendido como o objeto do encargo ou da tarefa do administrador, isto é, o ob- 
jeto da nomeação - e os atos que o administrador tem o poder de cumprir. Nesse ponto, a literatura jurídica tem trabalhado para distinguir essas duas situações jurídicas, averiguando se existe e qual seria a diferença entre eles e que implicações isso traria. Primeiramente, é preciso esclarecer que há dois questionamentos fundamentais à compreensão dessa problemática: 1) Existe diferença entre os sintagmas poderes do administrador e objeto da nomeação? e 2) $\mathrm{O}$ administrador pode exercer apenas os atos apontados expressamente pelo juiz ou também pode praticar os implícitos, depreendidos da interpretação do objeto do apoio?

A priori, não haveria diferença entre tais situações, pois ambas designariam os atos delimitados pelo juiz no Decreto de nomina. Nessa perspectiva, Maria Novella Bugetti defende serem tais termos distintos. $O$ oggetto dell'incarico seria a circunscrição do campo de atuação do amministratore, em que virá a desenvolver os atos indicados pelo juiz. Assim, o objeto seria necessariamente mais amplo que os atos expressamente delimitados pelo giudice tutelare, exceto na hipótese de nomeação de um administrador para o apoio em um só ato específico: "In questo senso, l'oggetto dell'amministrazione non equivarrebbe all'insieme delle funzioni di rappresentanza ("di agire in nome e per conto del beneficiario", ex art. 405, comma 3, n. 4) ovvero di assistenza del beneficiario; esso consisterebbe piuttosto nel "perimetro oggettivo» nel quale detti poteri e detto incarico debbono essere svolti" (BUGETTI, 2007, p. 42).

A partir dessa premissa em comum, surgem dois entendimentos diversos: o primeiro compreende que o administrador tem seus poderes de atuação indicados em numerus clausus no Decreto di nomina; e o segundo pressupõe que existem poderes e atos em numerus apertus, ou seja, mesmo não mencionados expressamente são permitidos de serem exercidos. Dessa forma, o primeiro sustenta que o objeto serve de "chave interpretativa" para que o administrador não extrapole os atos indicados pelo juiz. Com isso, o oggetto seria redutor da atividade do amministratore, podendo, inclusive, ser utilizado para uma eventual anulação de atos executados além de sua esfera de competência: "In questo senso, l'enunciazione dell'oggetto dell'amministrazione si atteggerebbe alla stregua di 'chiave interpretativa interna' del decreto di amministrazione e di delimitazione delle funzioni e dei poteri di questi" (BUGETTI, 2007, p. 43).

Já para o segundo ponto de vista, o objeto serviria ao propósito oposto, isto é, permitiria ao administrador exercer atos que, embora não indicados pelo juiz, sejam necessários à efetivação do escopo do oggetto dell'incarico.

O artigo 410 do Codice Civile versa acerca dos deveres atribuídos ao amministratore di sostegno durante o tempo de exercício da função. Seu dever geral - e principal - é garantir a consecução do melhor interesse do amministrato, conforme assinala Paolo Baccarani (2006, p. 160): "L'amministratore, quindi, dovrà essere scelto con esclusivo riguardo agli interessi del beneficiario, dovrà operare per la sua maggior felicità, agendo con la diligenza del buon padre di famiglia".

Entre os deveres específicos fixados na norma jurídica estão: 1) respeitar os desejos e aspirações do beneficiário, tendo a consciência de que o cuidado da pessoa se sobrepõe ao patrimônio (DI BELLO, 2014-2015, p. 28); 2) observar e respeitar os limites estabelecidos no decreto di nomina; 3 ) informar ao beneficiário sobre os atos que venham a ser realizados em relação ao apoio; 4) comunicar ao giudice tutelare acerca de eventuais dissensos com o amministrato; e 5) o dever de permanecer no cargo por mais de dez anos, nos casos em que seja cônjuge, convivente, descendente ou ascendente do administrado.

De igual maneira, tem o amministratore a obrigação de realizar a contabilidade de seu apoio, devendo submetê-la anualmente ao juízo tutelar, conforme artigo 380.

Por fim, ao cessar seu ofício como administrador, deve realizar um relatório final referente ao período em que exerceu a função (artigo 385). Caso o apoio incida sobre o patrimônio do beneficiário, é exigido do administrador a diligência que teria um homem médio (bonus pater familiæ), respondendo pelo dano causado em violação de seus deveres.

Há de se declarar também que o apoio prestado deve ser gratuito, sendo, por outro lado, facultado ao giudice tutelare determinar o pagamento de uma indenização ao amministratore, conforme o tamanho do patrimônio e a dificuldade da administração.

A título de exemplo, tem-se um recurso julgado em 2019 pelo Tribunale di Venezia (Seconda Sezione Civile), que versava sobre o caso do filho de uma beneficiária que firmou contrato com o administrador de sua mãe, estabelecendo o pagamento anual da quantia de $€ \$ 2.500,00$ a título de indenização pelo exercício do apoio. Tendo sido informado, o juiz tutelar determinou a substituição do amministratore (artigo 384), sob o 
fundamento da gratuidade do ofício fixada no artigo 379, e reafirmou, ainda, que a função deve ser exercida exclusivamente para a proteção do sujeito, e não por quaisquer outros interesses. De igual maneira, o Tribunal ratificou que o estabelecimento de uma indenização é facultado exclusivamente ao juiz (Tribunale di Venezia Seconda Sezione Civile. Decreto di 19 aprile 2019, no 3159, G.T. Dott. Alessandro Cabianca).

Além dos deveres também são impostas ao administrador certas limitações.

A legislação italiana impõe regras quanto aos atos exercidos pelo administrador, de modo a limitar sua potestade de atuação. Assim, em determinadas ocasiões, faz-se necessária a autorização do giudice tutelare e/ou, até mesmo, do Tribunal, para que possam ser praticados, seguindo o modelo:

- Atos que necessitam da autorização do giudice tutelare (artigo 374): 1) adquirir bens, com exceção dos necessários para o uso do apoiado, para economia doméstica e para a administração do patrimônio; 2) coletar capital; 3) consentir com o cancelamento de hipoteca ou penhor, 4) assumir obrigações, exceto se estiverem relacionadas a despesas necessárias para o mantimento do beneficiário ou para a administração ordinária de seu patrimônio; 5) aceitar heranças ou renunciar a elas, assim como aceitar doações ou legados sujeitos a condições ou a encargos; 6) firmar contratos de locação de imóveis por prazo superior a nove anos, ou que se estendam por mais de um ano após a data de término da amministrazione di sostegno, caso em que o apoio tem prazo de vigência determinado; e 7) pleitear direito do beneficiário em juízo, a menos que se trate de uma nova obra ou dano temido, ação possessória ou de despejo, e de ações para colher frutos ou que visem à obtenção de provimentos conservativos; e

- Atos que necessitam da autorização do Tribunal (artigo 375): 1) alienar bens, com exceção de frutos e móveis de fácil deterioração; 2) constituir penhor ou hipotecas; 3) prosseguir com partilha, ou requerê-la judicialmente; e 4) firmar compromissos, transações e aceitar concordatas.

Há situações em que é vedada a execução de certos atos por parte do administrador (artigo 378), quais sejam: 1) adquirir bens ou direitos, diretamente ou por meio de terceiros, pertencentes ao administrado, mesmo que em hasta pública; 2) locar bens do administrado, salvo se autorizado pelo giudice tutelare; e 3) tornar-se cessionário em qualquer relação jurídica que envolva o amministrato.

No Direito italiano verifica-se a possibilidade de conversão da inabilitazione ou interdizione em amministrazione di sostegno. Durante o curso da ação de revogação dos regimes de interdizione ou inabilitazione, há a possibilidade de sua conversão em amministrazione di sostegno. Assim, de acordo com o artigo 429, comma 3, quando parecer oportuno, cabe ao Tribunal, de ofício ou a requerimento, transmitir os atos ao giudice tutelare para que possa dar prosseguimento à constituição ou não da amminstrazione di sostegno.

Em caso de conversão por requerimento dos interessados, o chamado "ricorso" deve ser apresentado conjuntamente ao pedido de revogação da interdizione ou inabilitazione ao juiz competente.

Por outro lado, nos casos em que a amministrazione di sostegno mostrar-se inadequada à plena tutela do beneficiário e de seus direitos, e o juiz considerar cabível a inabilitazione ou interdizione, deve informar ao Ministério Público para que este requeira a constituição de uma destas figuras tutelares, conforme artigo 413, comma 3. Nestes casos, a amministrazione di sostegno apenas cessará com a nomeação do tutore ou curatore provisório, ou com a sentença que declara a interdição ou a inabilitação.

Deve-se atentar para o fato de que o giudice tutelare não transmite os atos para outro juiz ou tribunal; o Ministério Público inicia uma ação autônoma. Isso equivale a que não há conversão stricto sensu de amministrazione di sostegno para interdizione ou inabilitazione, mas, sim, a cessação de um instituto e o início de outro.

Por fim, cabe falar sobre a revogação da amministrazione di sostegno, que pode ser totalmente revogada ou ter apenas substituído o seu administrador. Há de se salientar que os pressupostos para a cessação da amministrazione di sostegno são diferentes daqueles necessários à substituição ou destituição do amministratore di sostegno.

Nesse sentido, tem-se:

- Cessação da amministrazione di sostegno: pode se dar quando: 1) tornar-se desnecessária, isto é, quando não estiverem mais presentes os requisitos do artigo 404; e 2) o instrumento de apoio se tornar impróprio/insuficiente à plena tutela do administrado, podendo, inclusive, ser "convertido" para inabilitazione ou interdizione; e 
- Substituição ou destituição do amministratore: pode se dar quando: 1) o exercício do apoio se tornar excessivamente oneroso para o amministratore e houver alguém apto para substituí-lo. (artigo 383); 2) não cumprir seus deveres de informação, determinados no artigo 410, comma 2, ab initio; 3) ocorrer contrasto entre administrador e administrado; 4) houver escolhas ou atos possivelmente danosos; 5) verificar-se negligência na persecução dos interesses ou na satisfação dos desejos e pedidos do administrado; 5) ser considerado culpado por negligência; 7) tiver cometido abuso de poder; 8) demonstrar-se ineficiente no cumprimento de seus deveres; 9) tornar-se indigno da função, ainda que por motivos estranhos à amministrazione di sostegno; e 9) tornar-se insolvente. Deve-se afirmar que a concreção dessas hipóteses não resulta na destituição automática e impreterível do amministratore. Tal decisão cabe ao giudice tutelare, sendo a destituição apenas uma das medidas que pode vir a adotar.

Para a confecção de tal requerimento estão legitimados: 1) o beneficiário; 2) o administrador; 3) o Ministério Público; e 4) qualquer um dos sujeitos do artigo 406. 0 artigo 413, comma 4, permite que o juiz proceda ao ato até mesmo de ofício se constatar que é idôneo para a plena realização da tutela do beneficiário.

O requerimento deve ser feito nos casos em que um desses sujeitos considere preenchidos os pressupostos para cessação do apoio ou para a substituição do administrador, devendo o beneficiário e o administrador de apoio serem informados de tal pedido. O juiz deverá buscar as informações necessárias e os meios instrutórios devidos para que possa proferir decreto motivato.

\section{COMO É A TOMADA DE DECISÃO APOIADA BRASILEIRA?}

A Lei no 13.146/2015 (Lei de Inclusão da Pessoa com Deficiência - Estatuto da Pessoa com Deficiência) inseriu no Código Civil o artigo 1.783-A, que disciplina a tomada de decisão apoiada e estabelece tanto seus aspectos materiais quanto o procedimento a ser observado para que tal instrumento de apoio seja aplicado.

A seguir apresentamos uma sistematização geral do regime jurídico da tomada de decisão apoiada previsto no artigo 1.783-A para uma posterior comparação com o instituto italiano da amministrazione di sostegno.

Quadro 1 - Sistematização geral do regime jurídico da tomada de decisão apoiada

Legitimidade para requerer
O próprio apoiado é legítimo para propor o pedido de tomada de apoio, iniciando o procedimento (§ 2 o do artigo 1.783-A). Não há previsão expressa quanto à exclusividade ou não da pessoa com deficiência quanto a essa legitimidade. Acerca desse aspecto, pode-se apresentar dois pontos de vista: 1) os mesmos legitimados para propor a curatela de interditos têm legitimidade para propor a tomada de decisão apoiada (FARIAS; ROSENVALD, 2019, p. 379). Tiago Oliveira da Silva salienta que, todavia, a instituição da medida será condicionada à concordância do apoiado e à "possibilidade de ajuste do mecanismo de apoio a partir da nomeação de um apoiador em atenção ao princípio do interesse fundamental ou do melhor interesse da pessoa com deficiência" (SILVA, 2017, p. 109); e 2) há uma taxatividade da legitimidade ativa para a propositura da tomada de decisão apoiada, pois se trataria de "ato personalíssimo, de legitimidade exclusiva daquele que dela se beneficiará, por isso, deve ser requerida pelo próprio interessado e nunca por terceiros" (MENEZES, 2017, p. 46). Esse foi, inclusive, o entendimento do Tribunal de Justiça do Estado do Rio Grande do Sul (TJRS) na Apelação Cível no 70072156904, quando decidiu que a legitimidade para o requerimento de tomada de decisão apoiada é exclusiva da pessoa com deficiência a ser apoiada, afinal, a lei a considera plenamente capaz (TJRS, Apelação Cível no 70072156904, 8a Câmara Cível, Rel. Des. Ricardo Moreira Lins Pastil, julgado em 9/3/2017). No mesmo sentido, o Enunciado no 639 da VIII Jornada de Direito Civil. 


\begin{tabular}{|c|c|}
\hline Beneficiário & $\begin{array}{l}\text { É a pessoa com deficiência, mas não é qualquer uma que pode se beneficiar do instituto. Dada a } \\
\text { natureza de ato jurídico voluntário da tomada de decisão apoiada, é requisito sine quæ non que } \\
\text { a pessoa a ser apoiada tenha discernimento - apesar da deficiência - e, por isso, capacidade para } \\
\text { exercer seus direitos e manifestar sua vontade. A par, no entanto, das disposições da Convenção } \\
\text { de Nova York de } 2007 \text { e da Lei de Inclusão Brasileira - que atribuem às pessoas com deficiência } \\
\text { a plena capacidade para exercer seus direitos -, infere-se, logicamente, que todas elas poderiam } \\
\text { se beneficiar do instituto, afinal todas passaram a poder exercer por si os direitos dos quais são } \\
\text { titulares. Cristiano Chaves de Farias e Nelson Rosenvald (2019, p. } 378 \text { ) entendem, todavia, que } \\
\text { as pessoas com deficiência que têm condições de exprimir sua vontade e se autodeterminar } \\
\text { podem, eventualmente, se beneficiar desse apoiamento; e as que não conseguem exprimir } \\
\text { vontade são relativamente incapazes, devendo ser submetidas à curatela, ainda que esta seja } \\
\text { excepcional e com um regime especial de atenção aos interesses da pessoa com deficiência. Nesse } \\
\text { mesmo sentido, há o Enunciado no } 640 \text { da VIII Jornada de Direito Civil. O juiz poderá denegar a } \\
\text { constituição da tomada de decisão apoiada quando: } 1 \text { ) verificar que o requerente não consegue } \\
\text { exprimir vontade ou não possui discernimento para praticar os atos da vida civil, hipótese na qual } \\
\text { caberia a curatela; } 2 \text { ) verificar que o requerente não se enquadra na definição de pessoa com } \\
\text { deficiência; ou 3) verificar que as cláusulas estão transferindo o poder de decidir para o apoiador, } \\
\text { e não auxiliando o apoiado para que ele próprio exerça sua capacidade. Nesse caso, o juiz pode } \\
\text { negar totalmente o pedido, ou parcialmente, apontando quais cláusulas são incompatíveis com } \\
\text { o instituto. Sendo um procedimento de jurisdição voluntária, indeferido o pedido, cabe apelação } \\
\text { da sentença (artigo } 724 \text { do Código de Processo Civil). }\end{array}$ \\
\hline $\operatorname{Rec}$ & $\begin{array}{l}\text { O pedido de constituição de tomada de decisão apoiada é realizado a partir de um termo a ser } \\
\text { homologado pelo juiz, no qual se especificam os limites do apoio e o compromisso dos apoiadores, } \\
\text { além de ser apresentado o prazo de vigência e o respeito à vontade, aos direitos e aos interesses } \\
\text { do apoiado. É um instrumento de caráter singular e individual, na medida em que é moldado e } \\
\text { adequado às respectivas necessidades, particularidades e limitações de cada sujeito a ser apoiado. }\end{array}$ \\
\hline $\begin{array}{r}\text { Pessoas } \\
\text { pelo } \mathrm{j}\end{array}$ & $\begin{array}{l}\text { O juiz, antes de homologar ou não o termo de constituição, deve realizar a oitiva do Ministério } \\
\text { Público e de uma equipe multidisciplinar. Após, ouvirá pessoalmente a pessoa com deficiência } \\
\text { que deseja ser apoiada e os apoiadores designados. O procedimento de decisão apoiada } \\
\text { começa a produzir efeitos desde a sua homologação pelo juiz. Esse processo burocrático } \\
\text { pode ser um desestímulo à constituição da tomada de decisão apoiada, na medida em que a } \\
\text { judicialização, mediante uma deficiente celeridade na tramitação dos processos judiciais, passa } \\
\text { a figurar como um empecilho à constituição do instituto (SCHREIBER, 2016). }\end{array}$ \\
\hline Prazc & $\begin{array}{l}\text { Há dúvidas sobre o prazo de vigência do acordo firmado, se pode ou não ser indeterminado } \\
\text { (sine die). Institutos estrangeiros similares à tomada de decisão apoiada possuem respostas } \\
\text { diferentes a essa dúvida (REQUIÃO, 2016, p. 43). Na Itália, o artigo } 405, \mathrm{~V}, 2 \text {, do Codice Civile, } \\
\text { estabelece que a amministrazione di sostegno pode ter prazo indeterminado. Já na França, a } \\
\text { sauvagarde de justice tem duração máxima de um ano, renovável apenas uma vez, segundo } \\
\text { prescreve o artigo } 439 \text { do Code. }\end{array}$ \\
\hline $\begin{array}{l}\text { Resi } \\
\text { (revog }\end{array}$ & $\begin{array}{l}\text { A tomada de decisão apoiada é ato voluntário da pessoa com deficiência. Logo, é um direito } \\
\text { disponível. Por isso, o § 9o do artigo 1.783-A permite que a pessoa apoiada, a qualquer tempo, } \\
\text { requeira a extinção do acordo. De igual maneira, é permitido ao apoiador pedir sua exclusão do } \\
\text { processo, cabendo ao juiz a decisão sobre tal desligamento. }\end{array}$ \\
\hline $\begin{array}{l}\text { Conversibilidade } \\
\text { recíproca entre } \\
\text { tomada de } \\
\text { decisão apoiada } \\
\text { e curatela de } \\
\text { interditos }\end{array}$ & $\begin{array}{l}\text { Questiona-se se o procedimento do apoiamento pode se converter em ação de curatela e vice } \\
\text { e versa (SILVESTRE; NEVES; GUSELLA, 2017). O fato de os dois processos serem de jurisdição } \\
\text { voluntária possibilitaria maior flexibilidade procedimental. Nesse sentido, Cristiano Chaves de } \\
\text { Farias e Nelson Rosenvald (2019, p. 378) compreendem ser possível a conversão recíproca. Por } \\
\text { outro lado, Joyceane Bezerra de Menezes entende não ser possível a conversão da curatela } \\
\text { em tomada de decisão apoiada de ofício pelo juiz, podendo apenas, ao julgar improcedente a } \\
\text { curatela, recomendar a tomada de decisão apoiada à pessoa com deficiência, ou ainda intimá- } \\
\text { lo para que manifeste seu interesse (MENEZES, 2018, p. 92). O apoiado pode, ainda, determinar } \\
\text { que seus apoiadores se tornem seus curadores, caso ele venha a ser curatelado, segundo } \\
\text { entendimento da segunda parte do Enunciado no } 639 \text { da VIII Jornada de Direito Civil. }\end{array}$ \\
\hline
\end{tabular}




\begin{tabular}{|c|c|}
\hline $\begin{array}{c}\text { Divergência } \\
\text { entre apoiador e } \\
\text { apoiado }\end{array}$ & $\begin{array}{l}\text { No caso de negócio jurídico em que possa trazer risco ou prejuízo relevante ao apoiado e } \\
\text { havendo divergência entre o apoiado e seus apoiadores, a questão deverá ser submetida ao } \\
\text { juiz, o qual, após ouvir o Ministério Público, deverá decidir acerca do impasse (§ } 60 \text { do artigo } \\
\text { 1.783-A). Essa intervenção judicial somente justifica-se em caso de risco ou prejuízo relevante, } \\
\text { de modo que em negócios jurídicos de menor valor não caberá tal interferência (REQUIÃo, } \\
2016, \text { p. 44). Nota-se que há a necessidade de uma justa causa, e não apenas a divergência, } \\
\text { para que haja uma participação ativa do juízo. Questiona-se se tal supressão da autonomia da } \\
\text { vontade do apoiado não significaria reconhecer sua incapacidade para deliberar acerca dos } \\
\text { atos de sua vida civil. Isto é, estaria a decisão do juiz, que contraria a vontade do apoiado, } \\
\text { a afirmar que este não é dotado de capacidade plena, devendo, então, ser submetido à } \\
\text { curatela? (Ainda que seja uma curatela flexível e proporcional, nos moldes do } \S 30 \text { do artigo } \\
84 \text { da Lei no } 13.146 / 2015) \text {. Pergunta-se, também, se o apoiado poderia pôr fim à tomada de } \\
\text { decisão apoiada quando pendente a decisão do juiz sobre os negócios jurídicos do } \S 60 \text { do } \\
\text { artigo } 1.783-A, \text { pois, caso o possa, surgiria a possibilidade de dissolver o procedimento de } \\
\text { apoio apenas para não ter de se submeter a uma eventual decisão do juiz que seja contrária } \\
\text { à sua vontade. }\end{array}$ \\
\hline Objeto & $\begin{array}{l}\text { A tomada de decisão apoiada pode estipular cláusulas sobre direitos patrimoniais ou existenciais. } \\
\text { O apoio pode consistir em auxílio para todos os negócios jurídicos patrimoniais realizados pelo } \\
\text { apoiado ou para tipos específicos. Pode, ainda, o apoio se dar sobre direitos existenciais (saúde, } \\
\text { privacidade e matrimônio). Quanto ao objeto do apoio - se recai sobre direitos patrimoniais e } \\
\text { existenciais em conjunto -, há pontos de vista divergentes. Para exemplificar, veja as seguintes } \\
\text { opiniões: 1) Joyceane Bezerra de Menezes (2017, p. 47) afirma que "ante a omissão legal, o } \\
\text { apoio pode se estabelecer quanto às questões patrimoniais e/ou às questões existenciais, nada } \\
\text { impedindo que também incida sobre decisões da rotina doméstica ou pertinentes aos cuidados } \\
\text { pessoais"; e 2) Flávio Tartuce (2019) entende que a extensão do objeto é limitada apenas para } \\
\text { atos de natureza patrimonial, de modo que caracteriza tal instrumento de apoio como de } \\
\text { "iniciativa da própria pessoa com deficiência, que tem à sua disposição meios mais simples } \\
\text { para o apoio de atos patrimoniais". As cláusulas do apoio não podem, todavia, transferir o } \\
\text { poder decisório para os apoiadores, existindo, para isso, o mandato, que não se confunde com } \\
\text { a tomada de decisão apoiada. }\end{array}$ \\
\hline \begin{tabular}{|c|} 
Validade e \\
eficácia das \\
decisões tomadas \\
pelo apoiado
\end{tabular} & $\begin{array}{l}\text { O } § 4 \text { o do artigo 1.783-A parece que estabelece a condição de que a decisão do apoiado } \\
\text { deve estar inserida nos limites do apoio acordado para que tenha validade e efeitos sem } \\
\text { restrições sobre terceiros. Assim, uma decisão tomada sem a participação dos apoiadores e, } \\
\text { portanto, fora do estabelecido pelo termo do apoio, poderá ser anulada, devendo o juiz aferir } \\
\text { as circunstâncias do caso para decidir. Maria Helena Diniz assevera que "com a homologação, } \\
\text { todos os atos negociais do apoiado deverão contar com a participação dos apoiadores" } \\
\text { (2019, p. 774), indicando a necessidade do apoio nos atos negociais. Questiona-se, ainda, } \\
\text { a obrigatoriedade do apoio nos atos de natureza existencial, e se as decisões nessa seara } \\
\text { necessitariam serem tomadas dentro dos limites do apoio para terem validade e eficácia } \\
\text { irrestritas perante terceiros. No sentido contrário, Joyceane Bezerra de Menezes (2018, p. 92) } \\
\text { entende que "os negócios realizados com terceiros, pelo apoiado, mesmo sem a participação } \\
\text { do apoiador, são válidos". }\end{array}$ \\
\hline
\end{tabular}

Fonte: Os autores.

\section{COMPARANDO A RATIO JURIS DOS INSTITUTOS}

Em primeiro lugar, é óbvio que toda comparação de experiências jurídicas estrangeiras, com a experiência jurídica brasileira em torno de determinado instituto, deve sempre considerar a cultura jurídica dos países envolvidos. Por essa razão, nesta pesquisa a comparação pretendida não realizará juízos de valor sobre o instituto italiano, mas apenas uma análise descritiva. Quanto ao instituto brasileiro, aí sim nos é dado realizar uma avaliação - e não mera descrição -, a partir dos elementos colhidos do instituto estrangeiro. Essa é a premissa da comparação aqui proposta. 
Ainda preliminarmente, é importante asseverar que a amministrazione di sostegno e a tomada de decisão apoiada são procedimentos com alto teor burocrático, o que é apontado - tanto no Brasil quanto na Itália - como fator desestimulante de sua constituição.

No Brasil, a tomada de decisão apoiada é um instituto concebido para os casos de deficiências física e mental/intelectual que não prejudicam o pleno discernimento. Para as hipóteses de deficiência severa, o $\S 1$ o do artigo 84 da Lei no.13.146/2015 prevê a possibilidade de uma curatela especial. Tanto é assim que a constituição da tomada, nos termos do caput do artigo 1.783-A, é um direito potestativo da pessoa com deficiência, o que significa que ela goza de plena ou parcial (porém suficiente) capacidade de compreensão da realidade que a cerca.

A amministrazione di sostegno, por sua vez, tem um rol de beneficiados mais amplo. Além de enfermos mentais e pessoas com deficiência física e psíquica - independentemente do grau de incapacitação -, o instituto de apoio pode estender-se a incapazes de fato, desde que a incapacidade decorra de uma deficiência/ enfermidade (por exemplo: Alzheimer, prodigalidade). Nesse sentido, são apontados dois critérios: subjetivo (menomazione ou enfermità) e objetivo (impossibilità).

A conclusão a que se chega é que a tomada de decisão apoiada é um direito potestativo da pessoa com deficiência que tem pleno ou parcial (suficiente) discernimento. Na Itália, todavia, a medida pode também ser aplicada a pessoas com deficiência ou enfermidade que estiverem impossibilitados, parcial ou temporariamente, de prover aos seus próprios interesses, tanto que a legitimidade para requerer o apoio não se restringe ao beneficiário, sendo ampliado a um rol de diversos sujeitos.

Nesse aspecto, a amministrazione di sostegno mais se aproxima da curatela do Brasil que à tomada de decisão apoiada. É que o instituto italiano foi inserido na legislação em 2004, antes, portanto, da Convenção de Nova York de 2007, que pleiteava a plena liberdade de exercício dos direitos pelas próprias pessoas com deficiência.

Tanto é assim que na tomada de decisão apoiada brasileira os apoiadores (pelo menos dois) têm função de conselheiros "para prestar-Ihe apoio na tomada de decisão sobre atos da vida civil, fornecendo-lhes os elementos e informações necessários para que possa exercer sua capacidade" (caput do artigo 1.783-A). Não praticam o ato pelo ou com o beneficiário.

Na Itália, o amministratore (que, a princípio, é somente um) pode - a depender da menomazione, enfermità e impossibilità - praticar os atos pelo amministrato à semelhança do que ocorre no Brasil com a representação legal e a assistência. Aqui, porém, os apoiadores não são representantes legais ou assistentes, não podendo praticar atos pelo apoiado. Poderão fazê-lo, porém, pela via do mandato (representação convencional).

No Brasil, a divergência entre apoiador(es) e apoiado somente será dirimida judicialmente nas hipóteses de "negócio jurídico que possa trazer risco ou prejuízo relevante" ( 6 60 do artigo 1.783-A). Na Itália, qualquer contrasto poderá ser resolvido pelo juiz.

Aliás, a intervenção judicial na vigência da amministrazione di sostegno é ampla. Tanto que os termos do apoio são fixados no Decreto di nomina. No Brasil, por sua vez, o juiz intervém em hipóteses excepcionais (divergências, destituição, exoneração, extinção), e os termos do apoiamento são fixados pelas próprias envolvidas em instrumento negocial particular, tendo o juiz função homologatória. Ou seja: enquanto a tomada de decisão apoiada tem verdadeira natureza negocial, a amministrazione di sostegno é muito mais um ato judicial (embora, é verdade, haja sim espaço para negociações, porém restritas).

A tomada versa sobre direitos patrimoniais e negociais (caput do artigo 85 da Lei no. 13.146/2015), e a amministrazione, por sua vez, pode incidir também sobre direitos fundamentais.

\section{CONCLUSÃO}

Não parece correta a afirmação de que a tomada de decisão apoiada é um instituto similar à amministrazione di sostegno. Se comparada à realidade brasileira, inaugurada pela Lei de Inclusão da Pessoa com Deficiência (Lei no 13.146/2015), o instituto italiano estaria próximo a uma modalidade de curatela, o que no Brasil se pretendeu restringir em casos de pessoas com deficiência para situações excepcionais e extremas. 
Assim, a amministrazione di sostegno pouco contribui para a operabilidade da tomada de decisão apoiada, o que não significa que o instituto italiano seja ruim; apenas que é tão diferente que não pode ser visto como correspondente ao apoiamento brasileiro.

Constatou-se, porém, que a amministrazione di sostegno preserva - ainda que por vezes de maneira reduzida - a autonomia da pessoa com deficiência. Por isso, esse modelo pode ser utilizado para a operabilidade do modelo de curatela especial prevista nos $\S \S 1$ 으, 3으 e 4으 do artigo 84 e artigo 85 da Lei №. 13.146/2015.

O artigo 114 da Lei no 13.146/2015 modificou o sistema das incapacidades de exercício do Código Civil, ou seja, a limitação (incapacidade relativa) ou a impossibilidade (incapacidade absoluta) de exercício dos direitos pelo próprio titular.

As alterações e revogações dos artigos 3ํ e 4ㅇ do Código Civil têm por objetivo atender à ratio juris e à ratio legis da Lei de Inclusão expressas no caput do artigo 84, quais sejam, considerar as pessoas com deficiência - independentemente de grau e condição - como plenamente capazes de praticar os atos da vida civil: "Art. 84. A pessoa com deficiência tem assegurado o direito ao exercício de sua capacidade legal em igualdade de condições com as demais pessoas".

A formulação normativa é clara em sua prescrição: a pessoa com deficiência tem capacidade civil plena tal e qual uma pessoa sem deficiência.

Ocorre que o caput do artigo 84 e o artigo 114, ambos do Estatuto da Pessoa com Deficiência, extinguiram as causas de incapacidades decorrentes de fatores intelectivos e as incapacidades que decorriam de problemas psicológicos ou psiquiátricos. Basicamente, então, extinguiu a incapacidade decorrente de deficiências intelectuais e enfermidades mentais; apenas os males psicológicos dos vícios em álcool e narcóticos e da prodigalidade foram mantidos como hipóteses de incapacidade relativa. Como consequência, não mais existe no Direito brasileiro a interdição de pessoa com deficiência; não há curatela de interditos perante a pessoa com deficiência em razão e por causa desta deficiência.

Pois bem. Analisando a ratio juris e a ratio legis da Lei no 13.146/2015, é possível concluir que a curatela prescrita nos artigos 84 e 85 é um tertium genus de representação, não sendo a mesma curatela dos interditos a que se referem os artigos 747 a 763 do Código de Processo Civil e os artigos 1.767 a 1.783 do Código Civil.

Essa curatela especial é uma verdadeira "grande novidade" da Lei de Inclusão da Pessoa com Deficiência; é uma figura inédita e que precisará ser construída com o tempo. Para ajudar nessa construção, verifica-se que o regime da amministrazione di sostegno pode oferecer importantes contribuições, pois, tal e qual uma curatela, a amministrazione é mais interventiva, porém participativa, pois assegura a participação do apoiado.

Desse modo, a pesquisa conclui que a amministrazione di sostegno não é correspondente à tomada de decisão apoiada (artigo 1.783-A do Código Civil), mas à curatela especial dos artigos 84 e 85 da Lei de Inclusão da Pessoa com Deficiência (Lei no 13.146/2015).

\section{REFERÊNCIAS}

BACCARANI, Paolo. L'amministratore di sostegno. Milano: Giuffrè, 2006.

BONILINI, Giovanni; TOMMASEO, Feruccio. Dell'amministrazione di sostegno: art. 404-413. II Codice Civile Commentario. 2. ed. Milano: Giuffrè, 2008.

BUGETTI, Maria Novella. L'amministrazione di sostegno tra tutela della persona e limiti di capacità. 2007. Tese (Doutorado) Alma Mater Studiorum Università di Bologna. Tutora Michele Sesta. Coordenadora Daniela Memmo. Bologna, 2007. Disponível em http://amsdottorato.unibo.it/id/eprint/97. Acesso em: 1o mar. 2020.

CASSANO, Giuseppe. L'amministrazione di sostegno: questione sostanziali e processuali nella'analisi della giurisprudenza. Matelica: Halley, 2006.

DI BELLO, Livia. Danno cagionato dal beneficiario dell'amministrazione di sostegno. 2015. Tesi (Laurea in Diritto Civile) - Libera Università Internazionale Degli Studi Sociali Guido Carli, Roma, 2014-2015. Orientador Michele Tamponi. Disponível em http:// tesi.luiss.it/16360/1/104093_DI\%20BELLO_LIVIA.pdf. Acesso em: 10 mar. 2020.

DINIZ, Maria Helena. Curso de Direito Civil brasileiro: Direito de família. 33. ed. São Paulo: Saraiva Jur, 2019.

FARIAS, Cristiano Chaves de; ROSENVALD, Nelson. Curso de Direito Civil - Parte Geral e Lindb. 17. ed. Salvador: JusPodivm, 2019. V. 1. 
GARGANI, Damiano. Verso la piena tutela dei soggetti deboli: I'amministrazione di sostegno. 2015-2016. Tese (Mestrado) Università di Pisa Dipartimento di Giurisprudenza, Pisa, 2015-2016. Orientadora Caterina Murgo. Disponível em: https://etd. adm.unipi.it/theses/available/etd-06282016-121617/unrestricted/TESI.pdf. Acesso em: 10 mar. 2020.

GURGEL, Fernanda Pessoa do Amaral. A eficácia prática da tomada de decisão apoiada. 2019. Tese (Doutorado) - Pontifícia Universidade Católica de São Paulo, São Paulo, 2019. Orientador professor doutor Oswaldo Peregrina Rodrigues. Disponível em: https://tede2.pucsp.br/handle/handle/22530. Acesso em: 1으 mar. 2020.

ITÁLIA. Corte di Cassazione Civile, I sez., no 25366, 29 nov. 2006.

ITÁLIA. Corte di Cassazione Civile, I sez., no 23.707, 20 dic. 2012.

ITÁLIA. Tribunale di Modena, decreto de 30 nov. 2014, G.T. dott. Roberto Masoni.

ITÁLIA. Tribunale di Modena, decreto de 5 nov. 2008, G. T. dott. Guido Stanzani.

ITÁLIA. Tribunale di Parma, decreto no 536 de 2 apr. 2004.

ITÁLIA. Tribunale di Mantova, decreto de 24 luglio 2008, G.T. dott. ssa. Jessica Bonetto.

ITÁLIA. Tribunale di Roma, decreto de 10 apr. 2009, G.T. dott. ssa. Chiara Giammarco.

ITÁLIA. Tribunale di Modena, decreto de 5 nov. 2008, G. T. dott. Guido Stanzani.

ITÁLIA. Tribunale di Parma, decreto no 536 del 2 apr. 2004.

ITÁLIA. Recurso julgado em 2019 pelo Tribunale di Venezia (Seconda Sezione Civile), Tribunale di Venezia Seconda Sezione Civile. Decreto di 19 apr. 2019, no 3159, G. T. dott. Alessandro Cabianca.

LEMOS, Tadeu. Transtornos por uso de substâncias. 2010. Disponível em http://www.saude.sc.gov.br/index.php/documentos/ atencao-basica/saude-mental/saude-mental-rede-hospitalar/curso-de-saude-mental-na-area-hospitalar/modulo-1/3900-tadeu-lemos-transtornos-por-uso-de-substancias/file. Acesso em: 15 fev. 2020.

MASONI, Roberto. Amministrazione di sostegno. Orientamenti giurisprudenziali e nuove applicazioni. Sant'Arcangelo di Romagna: Maggioli, 2009.

MENEZES, Joyceane Bezerra de. Tomada de decisão apoiada e sua correlação com institutos afins. In: Direito Civil: Estudos Coletânea do XV Encontro dos Grupos de Pesquisa - IBDCIVIL Série Direito Civil. São Paulo: Blucher, 2018. V. 1.

MENEZES, Joyceane Bezerra de. Tomada de decisão apoiada: instrumento de apoio ao exercício da capacidade civil da pessoa com deficiência instituído pela Lei Brasileira de Inclusão (Lei n. 13.146/2015). In:Revista Brasileira de Direito Civil RBDCivil, Rio de Janeiro, v. 9, n. 3, p. 31-57, 2017.

MONOSI, Stefania; TACCONE, Nicola. L’amministrazione di sostegno (Studio n. 623-2016/C). In: Studi e Materiali, Quaderni Trimestrali, Consiglio Naziole del Notariato, n. 4, Roma: Wolters Kluwer, 2016.

ORLANDO, Nicola. Gli interventi dell'amministratore di sostegno relativi agli atti di carattere personale del beneficiario. 2013. Tese (Doutorado) - Università Degli Studi di Padova, Padova, 2013. Orientador Renato Pescara. Disponível em: http://paduaresearch.cab.unipd.it/5782/1/NICOLA_Orlando-Tesidottorato.pdf. Acesso em: 1을. 2020.

REQUIÃO, Maurício. As mudanças na capacidade e a inclusão da tomada de decisão apoiada a partir do Estatuto da Pessoa com Deficiência. In: Revista de Direito Civil Contemporâneo, São Paulo, v. 6, p. 37-54, jan./mar. 2016.

RIBEIRO, lara Pereira. A capacidade civil de exercício de direitos e a tomada de decisão apoiada. In: Revista Brasileira de Direito Civil em Perspectiva, Curitiba, v. 2, n. 2, 2016.

RIO GRANDE DO SUL. Tribunal de Justiça. Apelação Cível no 70072156904. 8a Câmara Cível. Rel. Des. Ricardo Moreira Lins Pastil. Julgado em: 9/3/2017.

SCHREIBER, Anderson. Tomada de decisão apoiada: o que é e qual sua utilidade. In: Carta Forense, 2016. Disponível em: http:// www.cartaforense.com.br/conteudo/artigos/tomada-dedecisao-apoiada-o-que- e-e-qual-sua-utilidade/16608. Acesso em: 20 set. 2019.

SILVA, Tiago Oliveira da. Advento, leitura e aplicação da tomada de decisão apoiada. In: Revista IBDFAM: Família e Sucessões, Belo Horizonte: IBDFAM, v. 22, p. 89-114, jul./ago. 2017.

SILVESTRE, Gilberto Fachetti; NEVES, Guilherme Valli de Moraes; GUSELLA, Gabriela Azeredo. O procedimento de interdição à luz das alterações promovidas pelo Estatuto da Pessoa com Deficiência e pelo Código de Processo Civil de 2015. In: CONGRESSO DE PROCESSO CIVIL INTERNACIONAL, 2., 2017. Vitória. Anais [...]. Vitória: Ufes, 2017. V. 1.

TAKANEN, Flavio. Amministrazione di sostegno, interdizione ed inabilitazione: dottrina ed giurisprudenza. Milano: Key Editore, 2019. 


\section{Direito: Debate}

TARTUCE, Flávio. Direito de família e sucessões: desafios para o futuro. Primeira parte. In: Migalhas, 2019. Disponível em: https://flaviotartuce.jusbrasil.com.br/artigos/670284190/direito-de-familia-e-das-sucessoes-desafios-para-o-futuro-primeira-parte. Acesso em: 25 nov. 2019.

VIMERCATI, Benedetta. Dai requisiti di attivazione dell'amministrazione di sostegno alla necessità dell'interposizione del legislatore in materia di decisioni di fine vita (sulla sentenza di Cassazione civile, sez. I, 20 dic. 2012, n. 23707). In: Osservatorio dell'associazione Italiana dei Costituzionalisti. Disponível em: https://www.osservatorioaic.it/images/rivista/pdf/Nota\%20Vimercati.pdf. Acesso em: 20 jan. 2020. 